Journal of Engineering and Applied Sciences 14 (Special Issue 7): 10098-10101, 2019

ISSN: 1816-949X

(C) Medwell Journals, 2019

\title{
Statistical Analysis of the Total Annual (Maximum, Minimum) Temperatures and Total Annual Evaporation for the Period 2011-2017 for the Governorates of Babil and Najaf
}

\author{
Khawla Ali Abd Al-Hameed \\ Department of Soil Science and Water Resources, College of Agriculture, AL-Qasim Green University, \\ Babil, Hilla, Iraq
}

\begin{abstract}
The simple linear correlation coefficient (pearson) is a tool for people who work in statistical analysis. The aim of this study is to determine the required sample size (water level) to estimate the Pearson coefficient of correlation in terms of force and direction of total temperature variables (maximum, minimum). The annual total annual evaporation of Babil governorate was marked by the symbol $\mathrm{E}$ for the governorates of Babylon and Najaf during the period from 2011-2017. The result of the association of the total annual maximum temperatures and the total annual evaporation of the province of Babylon is strong and positive as a result of the correlation of the total of the minimum temperatures and the total annual evaporation of the province of Babylon is weak and positive, the total temperature (maximum, minimum) and total annual evaporation of Najaf governorate were weak and negative.
\end{abstract}

Key words: Linear correlation, coefficient, required sample, force and direction, evaporation, association

\section{INTRODUCTION}

Often the researcher needs to study the relationship between two or more variables. The correlation coefficient of Pearson is a dimensionless measurement that specifies a simple linear relationship between two variables. Its value varies from -1 , called a simple linear negative relationship, to +1 , called a fully positive simple linear relationship. When this value approaches zero, the simple linear correlation score is smaller. Of the correlation coefficient of Pearson, a number of other statistics were calculated such as partial correlation, direct and indirect effects of variables in path analysis and canonical association by Hair et al. and also in determining variables that could be used indirectly by CRUZ.

As a result, these statistics depend on the accuracy of Pearson's simple linear correlation coefficient. The size of the samples affects the statistical result and its interpretation. In large sample, low-volume coefficients generate a statistical result when the relationship parameters between them are not important in practice. Also, when the sample size is small, the reliability of the estimates is low and does not represent a real relationship between the two variables as by Hair CRUZ, Cargnelutti Filho et al. (2010), Cargnelutti Filho et al. (2011), Cargnelutti Filho et al. (2012), Sari et al. (2017), Goktas and Isci (2011), Neter et al. (1993) and Keller and Waracck (2001).

We conclude from this that the size of the appropriate sample is accurate. Finally, the aim of this study was to determine the sample size to estimate Pearson's simple linear correlation coefficient between total temperature variables (maximum, minimum) and total annual evaporation of Babil and Najaf governates. In this research, we know that the province of Babylon has a total area of $5116 \mathrm{~km}^{2}$ and the area of water bodies have $250 \mathrm{~km}^{2}$, Najaf province has a total area of $28,824 \mathrm{~km}^{2}$ and the area of water bodies have $200 \mathrm{~km}^{2}$. Can we prove that the water bodies of the province of Babylon are greater than the province of Najaf through the correlation coefficient of Pearson?

\section{CORRELATION}

Definition of correlation: The correlation means that there is a relationship between two phenomena or two variables, meaning that the change in one of the two variables leads to change in the other variable whether increase or decrease. If the two variables increase together and decrease together, the relationship between them is positive. If either one decreases by increasing the other variable, negative. The simplest way to study the relationship between the two variables or phenomena is the propagation mode. If we have $\mathrm{T}$ and $\mathrm{E}$ variables and these data are collected from the pairs of values of these two variables, they can be graphically represented in the propagation mode and take different forms (Fig. 1). The points are scattered unconnected to a specific direction indicating that there is no relationship between the two variables (T, E), (Fig. 2). Where the points are spread around a straight line where the values of $\mathrm{E}$ decrease with the increase of $\mathrm{T}$ values and we conclude that there is an 


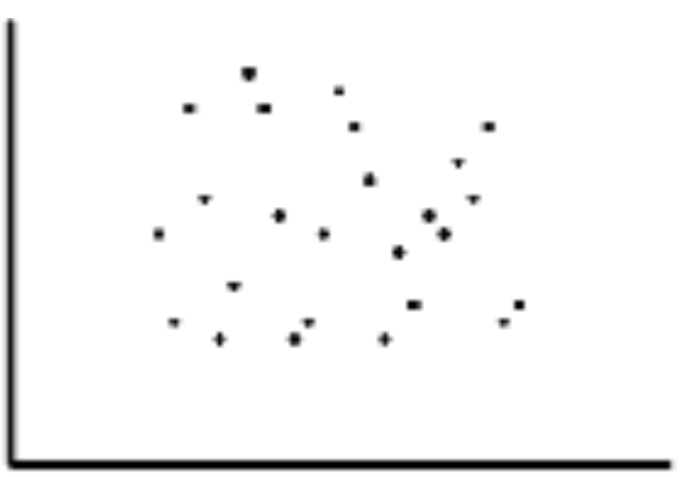

Fig. 1: The points are scattered unconnected to a specific direction indicating that there is no relationship between the two variables $(\mathrm{T}, \mathrm{E})$

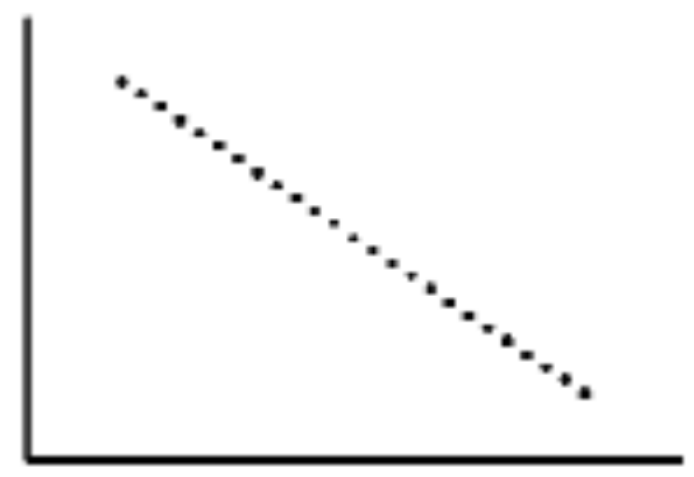

Fig. 2: Where the points are spread around a straight line where the values of $\mathrm{E}$ decrease with the increase of $\mathrm{T}$ values and we conclude that there is an inverse linear relationship between the variables $(\mathrm{T}, \mathrm{E})$

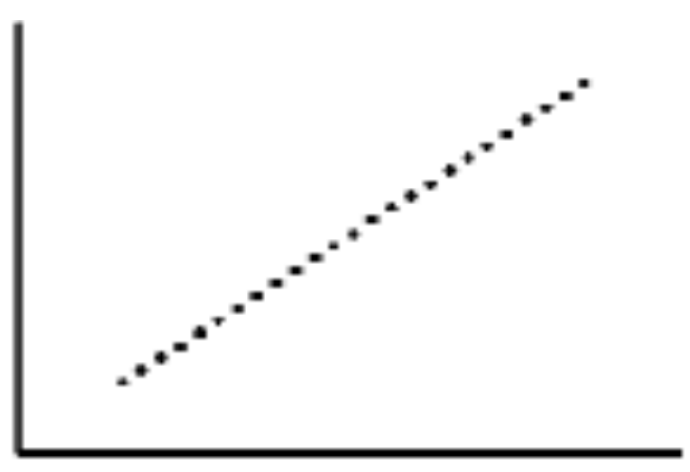

Fig. 3: Where the points are spread around a straight line in which the values of $\mathrm{T}$ increase with the values of $\mathrm{E}$

inverse linear relationship between the variables (T, E) (Fig. 3). Where the points are spread around a straight line in which the values of $\mathrm{T}$ increase with the values of

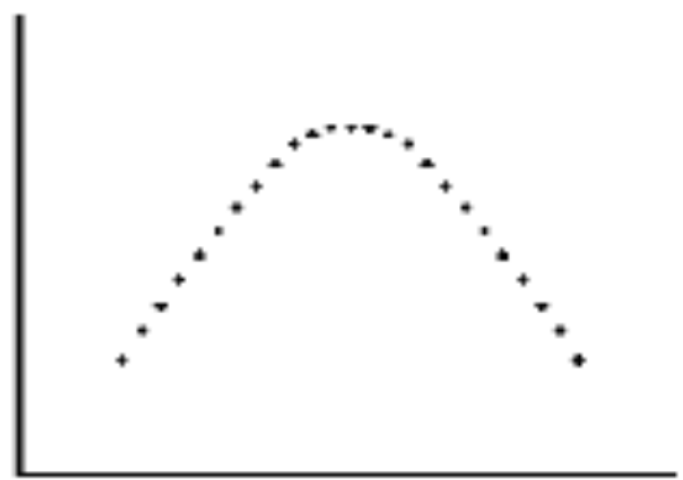

Fig. 4: Where the points are spread around the curve and we conclude that there is a non-linear relationship between the variables $(\mathrm{T}, \mathrm{E})$

Table 1: The value of correlation coefficients

\begin{tabular}{ll}
\hline Value of correlation coefficient & The meaning \\
\hline+1 & Correlation positive fully \\
From $0.70-0.99$ & Correlation positive strong \\
From $0.50-0.69$ & Correlation positive average \\
From $0.01-0.49$ & Correlation positive weak \\
0 & No correlation positive \\
\hline
\end{tabular}

$E$ and we conclude that there is a direct linear relationship between the variables (T, E), (Fig. 4) (Neter et al., 1993). Where the points are spread around the curve and we conclude that there is a non-linear relationship between the variables $(\mathrm{T}, \mathrm{E})$.

Simple linear correlation coefficient (Pearson): This link expresses the strength and direction of the relationship between two variables (phenomena) only, the result of the relationship either positive or negative on the one hand, strong or weak on the other.

Pearson assumes that they change as quantitative and that the relationship takes the form of a straight line Pearson represents the best measure between the two variables of correlation and symbolizes this parameter with the symbol $r$ and takes the following form:

$$
r=\frac{\sum_{i=1}^{n} T_{i} E_{i}-\left(\sum_{i=1}^{n} T_{i}\right)\left(\sum_{i=1}^{n} E_{i}\right) / n}{\sqrt{\sum_{i=1}^{n} T_{i}^{2}-\left(\sum_{i=1}^{n} T_{i}\right)^{2} / n\left(\sum_{i=1}^{n} E_{i}^{2}-\left(\sum_{i=1}^{n} E_{i}\right)^{2} / n\right)}}
$$

Correlation properties: What is said about the random correlation applies to the reverse correlation (with a negative signal) (Table 1).

Examples: These examples show how the total temperature (maximum, minimum) and total annual evaporation of the governorates of Babel and Najaf are correlated from 2011-2017. 
J. Eng. Applied Sci., 14 (Special Issue 7): 10098-10101, 2019

Table 2: The strength and direction of the relationshipbetween the maximum Temperature $(\mathrm{T})$ and the total annual Evaporation

\begin{tabular}{|c|c|c|c|c|}
\hline Years & & $\mathrm{T}$ & & $E$ \\
\hline 2011 & & 366.6 & & 1973.8 \\
\hline 2012 & & 387.5 & & 2159.4 \\
\hline 2013 & & 371.4 & & 2041.9 \\
\hline 2014 & & 385.6 & & 2070.8 \\
\hline 2015 & & 387.9 & & 2270 \\
\hline 2016 & & 383.5 & & 2078.5 \\
\hline 2017 & & 388.7 & & 2097.4 \\
\hline \multicolumn{5}{|c|}{ Solution } \\
\hline $\mathrm{T}$ & $E$ & ET & $\mathrm{T}^{2}$ & $E^{2}$ \\
\hline 366.6 & 1973.8 & 723595.08 & 134395.56 & 3895886.4 \\
\hline 387.5 & 2159.4 & 836767.5 & 150156.25 & 4663008.36 \\
\hline 371.4 & 2041.9 & 758361.66 & 137937.96 & 4169355.61 \\
\hline 385.6 & 2070.8 & 798500.48 & 148687.36 & 4288212.64 \\
\hline 387.9 & 2270 & 880533 & 150466.41 & 5152900 \\
\hline 383.5 & 2078.5 & 797104.75 & 147072.25 & 4320162.25 \\
\hline 388.7 & 2097.4 & 815259.38 & 151087.69 & 4399086.76 \\
\hline$\sum \mathrm{T}_{\mathrm{i}}=$ & $\sum E_{i}=$ & $\sum \mathrm{T}_{\mathrm{i}} \mathrm{E}_{\mathrm{i}}=$ & $\sum \mathrm{T}_{\mathrm{i}}^{2}=$ & $\sum \mathrm{E}_{\mathrm{i}}^{2}=$ \\
\hline 2671.2 & 14691.8 & 5610121.85 & 1019803.48 & 30888606.06 \\
\hline
\end{tabular}

Table 3: Relationship between the minimum Temperatureand the total annual Evaporation (E)

\begin{tabular}{|c|c|c|c|c|}
\hline Years & \multicolumn{3}{|c|}{$\mathrm{T}$} & $\mathrm{E}$ \\
\hline 2011 & \multicolumn{3}{|c|}{194.1} & 1973.8 \\
\hline 2012 & \multicolumn{3}{|c|}{205.7} & 2159.4 \\
\hline 2013 & \multicolumn{3}{|c|}{198.2} & 2041.9 \\
\hline 2014 & \multicolumn{3}{|c|}{206.7} & 2070.8 \\
\hline 2015 & \multicolumn{3}{|c|}{211.4} & 2270 \\
\hline 2016 & \multicolumn{3}{|c|}{203.3} & 2078.5 \\
\hline 2017 & \multicolumn{3}{|c|}{198.2} & 2097.4 \\
\hline \multicolumn{5}{|c|}{ Solution } \\
\hline $\mathrm{T}$ & E & ET & $\mathrm{T}^{2}$ & $E^{2}$ \\
\hline 194.1 & 1973.8 & 383114.58 & 37674.81 & 3895886.4 \\
\hline 205.7 & 2159.4 & 444188.58 & 42312.49 & 4663008.36 \\
\hline 198.2 & 2041.9 & 404704.58 & 39283.24 & 4169355.61 \\
\hline 206.7 & 2070.8 & 428034.36 & 42724.89 & 4288212.64 \\
\hline 211.4 & 2270 & 479878 & 44689.96 & 5152900 \\
\hline 203.3 & 2078.5 & 422559.05 & 41330.89 & 4320162.25 \\
\hline 198.2 & 2097.4 & 415704.68 & 39283.24 & 4399086.76 \\
\hline$\sum \mathrm{T}_{\mathrm{i}}=$ & $\sum E_{i}=$ & $\sum \mathrm{T}_{\mathrm{i}} \mathrm{E}_{\mathrm{i}}=$ & $\sum \mathrm{T}^{2}{ }_{\mathrm{i}}=$ & $\sum \mathrm{E}_{\mathrm{i}}^{2}=$ \\
\hline 1417.6 & 14691.8 & 2978183.83 & 287299.52 & 30888606.06 \\
\hline
\end{tabular}

Example: Between the strength and direction of the relationship between the maximum Temperature $(\mathrm{T})$ and the total annual Evaporation (E) of Babil governorate during the period from 2011-2017 (Table 2):

$$
\begin{gathered}
r=\frac{\sum_{i=1}^{n} T_{i} E_{i}-\left(\sum_{i=1}^{n} T_{i}\right)\left(\sum_{i=1}^{n} E_{i}\right) / n}{\sqrt{\sum_{i=1}^{n} T_{i}^{2}-\left(\sum_{i=1}^{n} T_{i}\right)^{2} / n\left(\sum_{i=1}^{n} E_{i}^{2}-\left(\sum_{i=1}^{n} E_{i}\right)^{2} / n\right)}} \\
r=\frac{5610121.85-5606390.88}{\sqrt{(473.56)(53036.454286)}} \\
r=\frac{3730.97}{5011.5809174028}=0.744
\end{gathered}
$$

Note that the relationship is positive and strong

Example: Between the strength and direction of the relationship between the minimum Temperature $(\mathrm{T})$ and the total annual Evaporation (E) of Babil governorate during the period from 2011-2017 (Table 3):
Table 4: Between the maximum Temperature (T) total annual Evaporation (E) of Najaf governorate

\begin{tabular}{lllll}
\hline Year & \multicolumn{3}{c}{$\mathrm{T}$} & \multicolumn{1}{c}{$\mathrm{E}$} \\
\hline 2011 & & 376.4 & & 2724.3 \\
2012 & & 389.9 & & 2685.8 \\
2013 & & 382 & & 2575.2 \\
2014 & & 389.4 & & 2464.2 \\
& & & & \\
2015 & & 395.4 & & 2598.7 \\
2016 & & 406.2 & & 2595.3 \\
2017 & & 399 & & 2686.1 \\
Solution & & & & $\mathrm{E}^{2}$ \\
\hline $\mathrm{T}$ & $\mathrm{E}$ & $\mathrm{ET}$ & $\mathrm{T}^{2}$ & 7421810.49 \\
376.4 & 2724.3 & 1025426.52 & 141676.96 & 7213521.64 \\
389.9 & 2685.8 & 1047193.42 & 152022.01 & 6631655.04 \\
382 & 2575.2 & 983726.4 & 145924 & 6072281.64 \\
389.4 & 2464.2 & 959559.48 & 151632.36 & 6753241.69 \\
395.4 & 2598.7 & 1027525.98 & 156341.16 & 6735582.09 \\
406.2 & 2595.3 & 1054210.86 & 164998.44 & 7215133.21 \\
399 & 2686.1 & 1071753.9 & 159201 & 2 \\
$\sum \mathrm{T}_{\mathrm{i}}=$ & $\sum \mathrm{E}_{\mathrm{i}}=$ & $\sum \mathrm{T}_{\mathrm{i}} \mathrm{E}_{\mathrm{i}}=$ & $\sum \mathrm{T}_{\mathrm{i}}^{2}=$ & $\sum \mathrm{E}^{2}{ }_{\mathrm{i}}=$ \\
2738.3 & 18329.6 & 7169396.56 & 1071795.93 & 48043225.8 \\
\hline & & & &
\end{tabular}

$$
\begin{aligned}
& r=\frac{\sum_{i=1}^{n} T_{i} E_{i}-\left(\sum_{i=1}^{n} T_{i}\right)\left(\sum_{i=1}^{n} E_{i}\right) / n}{\sqrt{\sum_{i=1}^{n} T_{i}^{2}-\left(\sum_{i=1}^{n} T_{i}\right)^{2} / n\left(\sum_{i=1}^{n} E_{i}^{2}-\left(\sum_{i=1}^{n} E_{i}\right)^{2} / n\right)}} \\
& r=\frac{2978183.83-2975299.3828571}{\sqrt{(259215.26857143)(53036.454286)}} \\
& r=\frac{2884.4471429}{117251.26328454}=0.024
\end{aligned}
$$

Note that the relationship is positive weak.

Example: Between the strength and direction of the relationship between the maximum Temperature ( $T$ ) and the total annual Evaporation (E) of Najaf governorate during the period from 2011-2017 (Table 4):

$$
\begin{aligned}
& r=\frac{\sum_{i=1}^{n} T_{i} E_{i}-\left(\sum_{i=1}^{n} T_{i}\right)\left(\sum_{i=1}^{n} E_{i}\right) / n}{\sqrt{\sum_{i=1}^{n} T_{i}^{2}-\left(\sum_{i=1}^{n} T_{i}\right)^{2} / n\left(\sum_{i=1}^{n} E_{i}^{2}-\left(\sum_{i=1}^{n} E_{i}\right)^{2} / n\right)}} \\
& r=\frac{7169396.56-7170277.6685714}{\sqrt{(612.0885715)(46906.348572)}} \\
& r=\frac{-881.1085714}{5358.2497041213}=-0.164
\end{aligned}
$$

Note that the relationship is negative weak.

Example: Between the strength and direction of the relationship between the minimum Temperature $(\mathrm{T})$ and the total annual Evaporation (E) of Najaf Governorate during the period from 2011-2017 (Table 5): 
Table 5: Relationship between the minimum Temperature (T) and the total annual Evaporation (E) of Najaf Governorate

\begin{tabular}{lllll}
\hline Year & \multicolumn{3}{c}{$\mathrm{T}$} & $\mathrm{E}$ \\
\hline 2011 & & 214.7 & & 2724.3 \\
2012 & & 228.2 & & 2685.8 \\
2013 & & 227.3 & & 2575.2 \\
2014 & & 234.2 & & 2464.2 \\
2015 & & 233.9 & & 2598.7 \\
2016 & & 233.1 & & 2595.3 \\
2017 & & 237 & & 2686.1 \\
Solution & & & & $\mathrm{E}^{2}$ \\
\hline $\mathrm{T}$ & $\mathrm{E}$ & $\mathrm{ET}$ & $\mathrm{T}^{2}$ & 7421810.49 \\
214.7 & 2724.3 & 584907.21 & 46096.09 & 7213521.64 \\
228.2 & 2685.8 & 612899.56 & 52075.24 & 6631655.04 \\
227.3 & 2575.2 & 585342.96 & 51665.29 & 6072281.64 \\
234.2 & 2464.2 & 577115.64 & 54849.64 & 6753241.69 \\
233.9 & 2598.7 & 607835.93 & 54709.21 & 6735582.09 \\
233.1 & 2595.3 & 604964.43 & 54335.61 & 7215133.21 \\
237 & 2686.1 & 636605.7 & 56169 & $\sum \mathrm{E}^{2}=$ \\
$\sum \mathrm{T}_{\mathrm{i}}=$ & $\sum \mathrm{E}_{\mathrm{i}}=$ & $\sum \mathrm{T}_{\mathrm{i}} \mathrm{E}_{\mathrm{i}}=$ & $\sum \mathrm{T}_{\mathrm{i}}^{2}=$ & 48043225.8 \\
1608.4 & 18329.6 & 4209671.43 & 369900.08 & 4
\end{tabular}

$$
\begin{gathered}
r=\frac{\sum_{i=1}^{n} T_{i} E_{i}-\left(\sum_{i=1}^{n} T_{i}\right)\left(\sum_{i=1}^{n} E_{i}\right) / n}{\sqrt{\sum_{i=1}^{n} T_{i}^{2}-\left(\sum_{i=1}^{n} T_{i}\right)^{2} / n\left(\sum_{i=1}^{n} E_{i}^{2}-\left(\sum_{i=1}^{n} E_{i}\right)^{2} / n\right)}} \\
r=\frac{4209671.43-4211618.3771428}{\sqrt{(335.71428572)(46906.348572)}} \\
r=\frac{-1946.9471428}{3968.2655287395}=-0.490
\end{gathered}
$$

Note that the relationship is negative weak.

\section{CONCLUSION}

After studying the simple linear correlation coefficient (Pearson) for the quantitative data of the total temperature (maximum, minimum) and total annual evaporation from 2011-2017 for the districts of Babylon and Najaf, it became clear to us that the water level of Babil province is greater than Najaf.

\section{REFERENCES}

Cargnelutti Filho, A., M. Toebe, C. Burin, T.R.D. Silveira and G. Casarotto, 2010. Sample size for estimating the Pearson correlation coefficient among corn characters. Braz. Agric. Res., 45: 1363-1371.

Cargnelutti Filho, A., S.J. Lopes, B. Brum, M. Toebe and T.R. da Silveira et al., 2012. Sample size to estimate the Pearson correlation coefficient among characters of castor bean. Semina Agric. Sci., 33: 953-962.

Cargnelutti Filho, A., S.J. Lopes, M. Toebe, T.R.D. Silveira and I.A. Schwantes, 2011. [Sample size to estimate the Pearson correlation coefficient among characters of Crambe abyssinica (In Portuguese)]. Agronomic Sci. Mag., 42: 149-158.

Goktas, A. and O. Isci, 2011. A comparison of the most commonly used measures of association for doubly ordered square contingency tables via. simulation. Methodol. Notes, 8: 17-37.

Keller, G. and B. Waracck, 2001. Statistics for Management and Economics. 6th Edn., Duxbury Press, California, USA.,.

Neter, J., W. Wasserman and G.A. Whitmore, 1993. Applied Statistics. 4th Edn., Allyn and Bacon, Boston, Massachusetts, USA., Pages: 989.

Sari, B.G., A.D.C. Lucio, C.S. Santana, D.K. Krysczun and A.L. Tischler et al., 2017. Sample size for estimation of the Pearson correlation coefficient in cherry tomato tests. Rural Sci., 47: 1-6. 